\title{
Production and characterization of monoclonal antibodies to Brazilian isolates of bovine viral diarrhea virus
}

L.C. Kreutz ${ }^{1,3}$, R. Donis², L.H.V. Gil' ${ }^{2}$ M. Lima', A.N. Hoffman ${ }^{1}$, D.C. Garcez ${ }^{1}$, E.F. Flores ${ }^{1}$ and R. W eiblen ${ }^{1}$

\section{Correspondence \\ L.C. Kreutz \\ Faculdade de Agronomia e M edicina Veterinária \\ Universidade de Passo Fundo \\ Campus I, Bairro São José \\ 99001-970 Passo Fundo, RS \\ Brasil \\ Fax: + 55-54-316-8152 \\ E-mail: Ickreutz@upf.tche.br \\ Research supported by MCT, CNPq, CAPES and FINEP (PRONEX em \\ Virologia Veterinária, No. 215/96) and FAPERGS (No. 96/1471.6). \\ E. Flores and R. W eiblen are recipients of CNPq fellowships (Nos. 352386/96 and 520011/95, respectively).}

Received January 19, 2000 Accepted September 19, 2000

\author{
${ }^{1}$ Laboratório de Virologia, Departamento de Medicina Veterinária Preventiva, \\ M icrobiologia e Parasitologia, Universidade Federal de Santa M aria, \\ Santa Maria, RS, Brasil \\ ${ }^{2}$ D epartment of Veterinary and Biomedical Sciences, \\ University of Nebraska at Lincoln, Lincoln, NE, USA \\ ${ }^{3}$ Faculdade de Agronomia e Medicina Veterinária, \\ Universidade de Passo Fundo, Passo Fundo, RS, Brasil
}

\section{Abstract}

Three Brazilian isolates of bovine viral diarrhea virus (BVDV), antigenically distinct from the standard North American isolates, were selected to immunize BALB/c mice in order to obtain hybridoma cells secreting anti-BVDV monoclonal antibodies (mAbs). Two hybridoma clones secreting $\mathrm{mAbs}$, reacting specifically with BVDV-infected cells (mAbs 3.1C4 and 6.F11), were selected after five fusions and screening of 1001 hypoxanthine-aminopterin-thymidine-resistant clones. These $\mathrm{mAbs}$ reacted in an indirect fluorescent antibody (IFA) assay with all 39 South and North American BVDV field isolates and reference strains available in our laboratory, yet failed to recognize other pestiviruses, namely the hog cholera virus. The mAbs reacted at dilutions up to 1:25,600 (ascitic fluid) and 1:100 (hybridoma culture supernatant) in IFA and immunoperoxidase (IPX) staining of BVDVinfected cells but only mAb 3.1C4 neutralized virus infectivity. Furthermore, both mAbs failed to recognize BVDV proteins by IPX in formalin-fixed paraffin-embedded tissues and following SDS-PAGE and immunoblot analysis of virus-infected cells, suggesting they are probably directed to conformational-type epitopes. The protein specificity of these mAbs was then determined by IFA staining of $\mathrm{CV}-1$ cells transiently expressing each of the BVDV proteins: mAb 3.1C4 reacted with the structural protein E2/gp53 and $\mathrm{mAb} 6 . \mathrm{F} 11$ reacted with the structural protein E1/gp25. Both mAbs were shown to be of the IgG2a isotype. To our knowledge, these are the first mAbs produced against South American BVDV isolates and will certainly be useful for research and diagnostic purposes.

\section{Introduction}

Bovine viral diarrhea virus (BVDV) is a small enveloped virus ubiquitous among cattle populations. The viral genome consists of a single-stranded, positive-sense RNA molecule of approximately $12.5 \mathrm{~kb}$ in length
Key words

- Bovine viral diarrhea virus

- Monoclonal antibodies

- Antigenic diversity

- Diagnostic reagents
$(1,2)$. The viral RNA genome contains a single open reading frame with a coding capacity of 3988 amino acids (1). Direct translation of the viral RNA genome yields a long polyprotein that is co- and post-translationally cleaved by cellular and virus-encoded proteases, giving rise to structural and 
non-structural viral proteins $(1,2)$. A small and basic protein is thought to form the viral nucleocapsid, and three glycoproteins, namely E0/gp48, E1/gp25 and E2/gp53 are inserted into the viral envelope (2). The nonstructural protein NS23/p125 is considered the most important protein involved in virus replication (3). Because of unique features of the viral genome, the NS23/p125 protein may be occasionally cleaved originating two additional products, NS2/p54 and NS3/p80 $(2,3)$. The production of NS3/p80 by some $\mathrm{BVDV}$ isolates is correlated with the production of cytopathology in cultured cells; such isolates are classified as cytopathic biotype. In contrast, most BVDV isolates express only the NS23/p125 polypeptide and do not produce cytopathology, being classified as non-cytopathic $(3,4)$. In addition, according to the nucleotide sequence of the 5 ' untranslated region of the viral genome, BVDV isolates might be classified as genotype 1 and 2 . Both cytopathic and non-cytopathic biotypes are found within each genotype $(5,6)$.

BVDV is the type species of the genus Pestivirus, within the family Flaviviridae, along with the hog cholera virus (HCV) and border disease virus of sheep (7). Clinical manifestations of BVDV infection include fever, mild acute or chronic diarrhea, respiratory disease, and hemorrhagic disease (8). Infection of seronegative pregnant cows with a non-cytopathic BVDV biotype may lead to embryonic or fetal deaths, abortion or fetal mummification, congenital malformations, stillbirths or the birth of weak or apparently healthy calves, many of which may be persistently infected with the virus (8). Persistently infected animals are the main source of BVDV infection to other animals in that they continuously shed viruses. In addition, mucosal disease, one of the most severe clinical manifestations of BVDV infection, occurs in persistently infected animals usually within the first two years after birth (8).
The classification of BVDV isolates into distinct biotypes and genotypes has been unequivocal, yet the grouping of field isolates according to their antigenic profile has been quite difficult. Several cross-neutralization studies have demonstrated a marked antigenic diversity among geographically distinct isolates (9-12). The antigenic variability among BVDV has been better defined by monoclonal antibody ( $\mathrm{mAb}$ )-based studies $(13,14)$. However, most existing mAbs have been produced against North American or European isolates of BVDV; consequently, it has been rather difficult to characterize South American BVDV isolates. In addition, the unavailability of $m A b$ against Brazilian isolates has hampered the characterization and phenotypic studies of BVDV in Brazil. Thus, local isolates of BVDV that were antigenically distinct from the standard BVDV strains (12), as determined by characterization with a panel of internationally available mAbs, were used to immunize BALB/c mice with the main objective of producing hybridoma cells secreting antiBVDV mAbs.

\section{Material and Methods}

\section{Cells and viruses}

Pestivirus-free Madin-Darby bovine kidney cells (MDBK, CCL-22; American Type Culture Collection, Rockville, MD, USA) were propagated in minimal essential medium (MEM) supplemented with $10 \%$ horse serum, $10,000 \mathrm{IU} / 1$ penicillin, $0.2 \mathrm{~g} / 1$ streptomycin, and $2.5 \mathrm{mg} / \mathrm{l}$ fungizone. $\mathrm{Sp} 2 \mathrm{my-}$ eloma cells were propagated in RPMI medium (Sigma Chemical Co., St. Louis, MO, USA) supplemented with $10 \%$ fetal bovine serum (FBS; Gibco-BRL, Rockville, MD, USA), $50 \mu \mathrm{g} / 1$ 8-azaguanine (Sigma), $1 \mathrm{mM}$ sodium pyruvate (Sigma), $2 \mathrm{mM}$ L-glutamine (Sigma), 0.01\% 2-mercaptoethanol (Sigma), and antibiotics as stated above, in a humidified chamber with $5 \% \mathrm{CO}_{2}$. Three 
BVDV isolates (UFSM-1, SV-63 and SV153.1) that were shown to be antigenically distinct from the standard BVDV laboratory strains (12) were chosen for mouse immunization.

\section{Antigen production and mouse immunization}

The BVDV isolates were biologically cloned three times by limiting dilution and used to infect MDBK cells to produce antigen for mouse immunization. Cells were infected at a multiplicity of infection of 0.1 to 1.0 cell culture infectious dose $\left(\mathrm{CCID}_{50}\right) /$ cell and the cell supernatant was collected at $72 \mathrm{~h}$ postinfection. Following centrifugation at $25,000 \mathrm{~g}$ for $10 \mathrm{~min}$ to remove cell debris, the virus suspension was mixed with a solution of polyethylene glycol (PEG, MW 8000; Sigma) and $\mathrm{NaCl}$ to achieve a final concentration of $7 \%$ and $0.4 \mathrm{M}$, respectively, and stirred at $4^{\circ} \mathrm{C}$ for $4 \mathrm{~h}$. The viral particles were pelleted from the solution by centrifugation at $65.000 \mathrm{~g}$ for $30 \mathrm{~min}$ at $4^{\circ} \mathrm{C}$, and resuspended in MEM at 1/100 of the initial volume. The concentrated virus was titrated on MDBK cells and aliquots were stored at $-70^{\circ} \mathrm{C}$. Concentrated virus was mixed with an equivalent volume of adjuvant and injected intraperitoneally (ip) into BALB/c mice $(200 \mu 1$ in Freund's complete adjuvant at day 0 and $200 \mu 1$ in Freund's incomplete adjuvant at 14, 28, 42, 56 and 70 days after the first injection). Two hundred microliters of concentrated virus without adjuvant was injected ip 3 days prior to removal of the mouse spleen and cell fusion.

\section{Cell fusion, hybridoma selection and screening}

Three days prior to fusion, the mice were boosted with an ip injection of adjuvant-free concentrated virus. The spleen was removed and minced and the obtained lymphocytes were mixed with Sp2 cells at a proportion of $10: 1$. Cell fusion was induced with $50 \%$
PEG (MW 1500; Sigma) for $1 \mathrm{~min}$ at $37^{\circ} \mathrm{C}$, followed by slow addition of RPMI medium. The cells were then plated onto 96-well plates containing hypoxanthine-aminopterin-thymidine medium (Sigma) supplemented with $15 \%$ FBS and $20 \%$ conditioned media. Expanding hybridomas were detected 7 to 10 days after fusion and the supernatant was tested for the presence of mAbs by immunoperoxidase (IPX) or indirect fluorescent antibody (IFA) staining. Hybridoma cells secreting BVDV-specific mAbs were then cloned and their reactivity to several BVDV isolates was determined by IFA.

\section{IPX and IFA staining}

The presence of mAbs in the supernatant of expanding hybridomas was tested on MDBK cells infected with BVDV isolate UFSM-1. IPX was performed on 96-well plates containing BVDV-infected cell monolayers fixed with $35 \%$ acetone. One hundred microliters of undiluted hybridoma supernatant was incubated with infected and noninfected cells for $1 \mathrm{~h}$ at $37^{\circ} \mathrm{C}$. After washing, horseradish peroxidase-conjugated antimouse immunoglobulin (Sigma) was added and incubated as above. After removal of the conjugate, color development was observed following the addition of the substrate solution (3-amino-9-ethylcarbazole; Sigma). For IFA staining, MDBK cells infected with BVDV isolate UFSM-1 and non-infected MDBK cells were individualized by trypsinization and dropped on 12-spot Teflon slides. Following adhesion, cells were fixed with acetone, dried and incubated with undiluted medium collected from expanding hybridomas for $1 \mathrm{~h}$ at $37^{\circ} \mathrm{C}$. Fluorescein isothiocyanate (FITC)-labeled anti-mouse immunoglobulin (Sigma) was added and incubated as above.

\section{Production of ascitic fluid}

For each hybridoma secreting anti-BVDV 
$\mathrm{mAbs}, 10 \mathrm{BALB} / \mathrm{c}$ mice were primed with Freund's complete adjuvant (Sigma) and 7 days later were injected ip with approximately $10^{6}$ hybridoma cells. Ten days later the ascitic fluid was collected from the mice, cleared by low speed centrifugation, titrated, aliquoted and stored at $-70^{\circ} \mathrm{C}$.

\section{Characterization of the mAbs}

The BVDV-specific mAbs secreted by hybridoma clones 3.1C4 and 6.F11 were characterized regarding immunoglobulin class, capacity to neutralize virus infectivity, spectrum of reactivity with different BVDV isolates, and ability to react with BVDV antigens in routinely fixed histological sections and in Western immunoblot. The immunoglobulin class and subclass of mAbs 3.1C4 and 6.F11 were determined using a commercially available kit, according to the manufacturer's recommendations (Mouse Type Isotyping kit, Bio-Rad, Hercules, CA, USA). To investigate the capacity of the $\mathrm{mAbs}$ to neutralize virus infectivity, serial 2fold dilutions of the respective ascitic fluid were mixed with $100 \mathrm{CCID}_{50}$ of BVDV UFSM-1 isolate and incubated for $1 \mathrm{~h}$ at $37^{\circ} \mathrm{C}$. A suspension of MDBK cells was then added to the wells and the plates were incubated at $37^{\circ} \mathrm{C}$ in the presence of $5 \% \mathrm{CO}_{2}$. Virus neutralization or growth was monitored by IFA staining of cells, as described above. The spectrum of reactivity of mAbs 3.1C4 and 6.F11 was assessed by staining cell monolayers infected with BVDV field isolates and reference strains and by staining $2 \mathrm{HCV}$ isolates with IFA (Table 1). The ability of the mAbs to react with BVDV antigens after routine formalin fixation and paraffin embedding was investigated by IPX staining according to previously described protocols, using $\mathrm{mAb} 15 \mathrm{c} 5$ as positive control (15). The ability of these $m A$ bs to recognize viral proteins resolved by SDS-PAGE and immobilized on nitrocellulose membranes was investigated by Western immu- noblot analysis of BVDV-infected cell lysates, performed according to standard protocols (16).

\section{Protein specificity of mAbs 3.1C4 and 6.F11}

To determine the $\mathrm{mAb}$ protein specificity, CV-1 cells transfected with plasmid constructs that express BVDV proteins (see below) were fixed with acetone:methanol (1:1) and incubated with ascitic fluid diluted 1:100 or 1:500 for $1 \mathrm{~h}$ at room temperature. The ascitic fluid was then washed and the cells were flooded with FITC-labeled goat antimouse antibody (Sigma). Staining of infected cells was observed by fluorescence microscopy.

\section{Transient expression of BVDV proteins}

Confluent CV-1 cells (African Green monkey kidney, ATCC-CCL 70) were infected with a recombinant vaccinia virus expressing phage T7 RNA polymerase (vTF7-3) (17) at an input multiplicity of 5 for $45 \mathrm{~min}$ at $37^{\circ} \mathrm{C}$. DNA-lipid complexes were prepared at room temperature using lipofectamine (Gibco-BRL) and DNA at a weight ratio of $12: 1$, as recommended by the manufacturer. Immediately following infection, CV-1 cells were washed three times with Dulbecco's minimal essential medium (DMEM, Gibco) without serum and transfected with $0.50 \mathrm{ng}$ of each of five plasmid constructs that comprise the entire polyprotein of BVDV strain NADL (18). The DNAlipofectamine complexes were incubated with cells at $37^{\circ} \mathrm{C}$ in the presence of $5 \% \mathrm{CO}_{2}$ for $4 \mathrm{~h}$. After lipofection, the DNA-lipid complexes were removed and the cells were supplemented with DMEM and 10\% FBS for an additional $13 \mathrm{~h}$, when the cells were fixed for IFA analysis.

\section{Results}

The fusion experiments that yielded hy- 
bridoma cells secreting anti-BVDV mAbs were performed using virus antigens from cells infected with the isolate UFSM-1 (12). Following five fusions of lymphocytes and myeloma cells, several expanding hybridoma cells were found to be reactive to BVDVinfected cells. However, only two hybridoma clones (3.1C4 and 6.F11) were stabilized and found to secrete specific mAbs against BVDV proteins; several other hybridoma clones secreted $\mathrm{mAbs}$ that were also reactive to cellular components. These mAbs have not been further characterized.

Both mAbs were reactive by IFA to all 32 South American isolates and several US isolates of BVDV, including viruses from both genotypes (BVDV type 1 and 2), but not to two HCV isolates (Table 1). The BVDVspecific $\mathrm{mAb}$-secreting hybridoma cells were then cloned and were used to produce mAbs either in cell culture or by injection of the hybridoma cells into BALB/c mice to obtain ascitic fluid.

Hybridoma supernatant and ascitic fluid derived from clones 3.1C4 and 6.F11, that were found to react specifically with BVDVinfected cells by IFA and IPX, yielded a positive signal by IFA even when diluted up to 100 (supernatant) and 25,600 times (ascitic fluid). Both mAbs were shown to belong to the IgG2a isotype. Only mAb 3.1C4 had neutralizing activity $(1: 80)$ against BVDV parental virus (UFSM-1, data not shown). This $\mathrm{mAb}$ also showed neutralizing activity against the BVDV Singer strain and against a BVDV type 2 cytopathic virus, although at lower titers. The protein specificity of the mAbs could not be determined by Western immunoblot analysis of lysates obtained from BVDV-infected cells. The $\mathrm{mAbs}$ did not react with viral proteins separated by SDS-PAGE and transferred to nitrocellulose membranes (data not shown), suggesting they are probably directed to conformational-type epitopes. Likewise, the mAbs failed to react with viral proteins by IPX in tissues submitted to routine formalin fixa- tion and paraffin embedding. However, using a transient BVDV-protein expression system, it was demonstrated that mAb 3.1C4

Table 1 - Reactivity of mAbs 3.1C4 and 6.F11 with BVDV isolates by IFA.

cp: Cytopathic; ncp: non-cytopathic; cp/ncp: mixture of cytopathic and non-cytopathic viruses; nd: not determined; n/a: not applicable. aLaboratório de Virologia, Universidade Federal de Santa Maria; bLaboratório de Virologia, Universidade Federal do Rio Grande do Sul; 'Centro de Pesquisas Veterinárias Desidério Finamor; dinstituto Biológico de São Paulo; eInstituto Nacional de Tecnologia Agropecuaria (INTA), Castelar, Argentina; ${ }^{\mathrm{f}}$ National Animal Disease Center, Ames, IA, USA; 9 Comell University, NY; ${ }^{h}$ classical swine fever virus; (+) positive reaction; (-) negative reaction.

\begin{tabular}{|c|c|c|c|c|c|}
\hline Isolate & Origin & Biotype & Genotype & $\mathrm{mAb} 3.1 \mathrm{C} 4$ & mAb 6.F11 \\
\hline UFSM.1 $1^{a}$ & Farroupilha, RS & ncp & 1 & + & + \\
\hline UFSM.2 & Alegrete, RS & ncp & 1 & + & + \\
\hline UFSM.3 & Pelotas, RS & ncp & 1 & + & + \\
\hline UFSM.4 & São Sepé, RS & ncp & nd & + & + \\
\hline UFSM.5 & São Sepé, RS & ncp & nd & + & + \\
\hline SV 123.4 & Santa Maria, RS & ncp & 2 & + & + \\
\hline SV 126.1 & Santa Maria, RS & ncp & 1 & + & + \\
\hline SV 126.8 & Farroupilha, RS & ncp & 1 & + & + \\
\hline SV 126.14 & Santa Maria, RS & ncp & 1 & + & + \\
\hline SV 152 & Farroupilha, RS & ncp & 1 & + & + \\
\hline SV 153.1 & Lavras do Sul, RS & ncp & 1 & + & + \\
\hline SV 153.15 & Lavras do Sul, RS & ncp & 1 & + & + \\
\hline SV 153.19 & São F. de Assis, RS & ncp & 1 & + & + \\
\hline SV 63 & Santa Maria, RS & ncp & 2 & + & + \\
\hline SV 260 & Lages, SC & ncp & 2 & + & + \\
\hline SV-228/98 & Carazinho, RS & ncp & nd & + & + \\
\hline LV85/96b & Viamão, RS & ncp & 2 & + & + \\
\hline EVI-006c & Eldorado do Sul, RS & ncp & 1 & + & + \\
\hline IBSP-1d & J aboticabal, SP & ncp & 1 & + & + \\
\hline IBSP-2 & J aboticabal, SP & $\mathrm{cp} / \mathrm{ncp}$ & 1 & + & + \\
\hline IBSP-4 & Ribeirão Preto, SP & $\mathrm{cp} / \mathrm{ncp}$ & 1 & + & + \\
\hline IBSP-5 & Ribeirão Preto, SP & $\mathrm{cp} / \mathrm{ncp}$ & 1 & + & + \\
\hline INTA $1^{\mathrm{e}}$ & Argentina & $\mathrm{cp} / \mathrm{ncp}$ & 1 & + & + \\
\hline INTA 2 & Argentina & ncp & 1 & + & + \\
\hline INTA 3 & Argentina & $\mathrm{cp} / \mathrm{ncp}$ & 1 & + & + \\
\hline INTA 4 & Argentina & $\mathrm{cp} / \mathrm{ncp}$ & 1 & + & + \\
\hline INTA 5 & Argentina & ncp & 1 & + & + \\
\hline INTA 6 & Argentina & ncp & 1 & + & + \\
\hline INTA 7 & Argentina & ncp & 1 & + & + \\
\hline $1 \mathrm{R}$ & Argentina & $\mathrm{cp} / \mathrm{ncp}$ & nd & + & + \\
\hline $34 \mathrm{P}$ & Argentina & $\mathrm{cp} / \mathrm{ncp}$ & nd & + & + \\
\hline $34 \mathrm{~B}$ & Argentina & $\mathrm{cp} / \mathrm{ncp}$ & nd & + & + \\
\hline $\mathrm{NADL}^{f}$ & USA & $c p^{j}$ & 1 & + & + \\
\hline SINGER & USA & $\mathrm{cp}$ & 1 & + & + \\
\hline OREGON & USA & $\mathrm{cp}$ & 1 & + & + \\
\hline BVDV 890 & USA & $\mathrm{cp} / \mathrm{ncp}$ & 2 & + & + \\
\hline VS-253 & USA & $\mathrm{cp}$ & 2 & + & + \\
\hline NY-939 & USA & ncp & 2 & + & + \\
\hline VS-191 & USA & ncp & 2 & + & + \\
\hline CSFVh & USA & ncp & $\mathrm{n} / \mathrm{a}$ & - & - \\
\hline CSFV & Brazil & ncp & $\mathrm{n} / \mathrm{a}$ & - & - \\
\hline
\end{tabular}


reacts with $\mathrm{E} 2 / \mathrm{gp} 53$ and $\mathrm{mAb} 6 . \mathrm{F} 11$ reacts with E1/gp25 (Table 2 and Figure 1).

\section{Discussion}

The clinical syndromes associated with BVDV infection result in severe economic losses to the cattle industry around the world. In endemic areas, the prevalence of BVDV antibodies among adult cattle may reach up to 70 to $80 \%$ (19). Because of their RNA genome and ubiquitous nature, a marked antigenic and genetic heterogeneity is observed among field BVDV isolates, repre-

Table 2 - Determination of the BVDV protein specificity of mAbs 3.1C4 and 6.F11.

Protein specificity was determined by indirect fluorescent antibody assay of CV-1 cells expressing each protein, using the hybridoma supernatant as primary antibody. (-) Negative reaction; (+) positive reaction.

mAb Recombinant protein expressed on CV-1 cells

E1/gp25 E2/gp53 NS3/p80 NS4B/p32 NS5A/p58 NS5B/p75

$\begin{array}{lllllll}3.1 \mathrm{C} 4 & - & + & - & - & - & - \\ 6 . \mathrm{F} 11+ & - & - & - & - & -\end{array}$

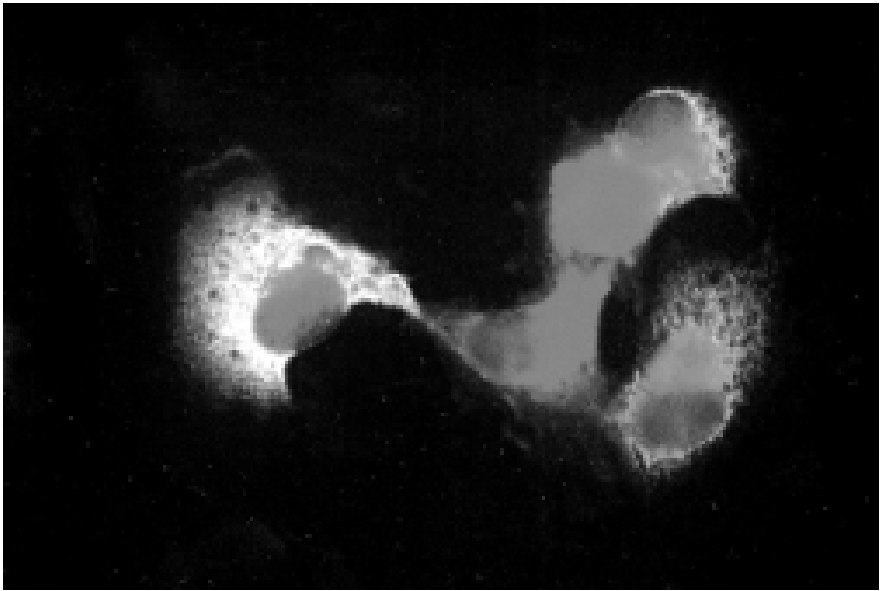

Figure 1 - Indirect fluorescent antibody (IFA) assay of CV-1 cells transfected with a plasmid encoding the BVDV glycoprotein E2/gp53 gene under the control of the phage T7 polymerase promoter. CV-1 cells were infected with a recombinant vaccinia virus expressing the phage T7 polymerase and then transfected with the plasmid. Cells were fixed $16 \mathrm{~h}$ after transfection and stained with IFA using mAb 3.1C4 as primary antibody. senting a problem for diagnosis and vaccine development (10). Thus, to identify potential vaccine candidate strains, it is necessary to perform phenotyping studies in order to identify the isolates that are representative of the viruses circulating among a given cattle population. These local isolates are more likely to elicit an immune response that is protective to most isolates prevalent in the area than viral strains derived from other geographic locations. Phenotyping studies of BVDV were made possible only after the production of $\mathrm{mAbs}$ to laboratory reference strains. Furthermore, mAbs are considered a powerful tool for research and diagnostic purposes.

Recently, several reports have demonstrated that BVDV is highly prevalent in Brazilian cattle $(12,16,20)$, and as such, it is probably associated with significant economic losses to the national livestock industry. These reasons prompted us to initiate epidemiological studies on BVDV infection followed by antigenic and molecular characterization of BVDV circulating in Brazilian cattle. Although the production of $m A b s$ to several BVDV isolates has already been reported, most of these mAbs have been produced against North American and European strains $(9,13,14,21)$. In addition, most of these mAbs were produced against laboratory reference strains rather than against field virus isolates. In a recent study, we have demonstrated that the BVDV viruses isolated in Brazil display marked antigenic differences when compared to North American reference strains $(12,16)$. We understand that the production of mAbs to Brazilian BVDV field isolates, antigenically distinct from the standard strains, will help in better defining the antigenic properties of these isolates and in designing more effective diagnostic tools and vaccines.

The low number of hybridoma clones secreting BVDV-specific mAbs obtained in the present study may be attributed to problems inherent to the technique per se, and to 
the peculiar biological properties of the pestiviruses as well. These include the inability of some viral isolates to replicate to high titers in cell culture, the poor antigenicity of BVDV to BALB/c mice and the difficulties in achieving a pure and concentrated suspension of viral particles for mouse immunization. The two mAbs obtained so far failed to recognize viral protein following SDS-PAGE and immunoblot analysis of infected cells, suggesting that they recognize conformational-type epitopes. Consequently, the identification of the protein specificity of these $\mathrm{mAbs}$ was made possible only by using a transient protein expression system in which BVDV proteins were expressed individually on $\mathrm{CV}-1$ cells. Both mAbs reacted with viral structural proteins: $\mathrm{mAb}$ 6.F11 reacted with glycoprotein E1/gp25 and mAb 3.1C4 reacted with glycoprotein E2/gp53.

Most mAbs against BVDV and other pestiviruses produced to date fall into two major groups: the first group comprises the pan-pestivirus mAbs, which recognize most pestivirus isolates and are mostly directed at the non-structural polypeptide NS23/p125 $(9,13,14,21)$. NS23/p125 is a multifunctional protein ultimately involved in viral RNA replication, and is highly conserved among pestiviruses (3). The other group comprises the type-specific mAbs, which are able to distinguish between strains or virus clusters possessing slight antigenic differences. Most of these mAbs are directed to the envelope glycoproteins E0/gp48 and E2/gp53 (9,13, $14,22)$. Glycoprotein E2/gp53 is the major envelope glycoprotein and is believed to play a major role in the initial interactions of virions with cell membrane proteins during virus attachment and penetration (3). This viral glycoprotein contains at least three highly variable regions and is a major target for neutralizing antibodies $(3,21,22)$.

Cellular receptor-binding proteins usually contain highly conserved domains that mediate specific interactions with cellular components $(23,24)$. These conserved re- gions, usually inaccessible to antibody binding, are often surrounded by variable regions that allow viruses to escape from the immune response $(23,24)$. Thus, mAbs directed at these variable regions usually fail to recognize a considerable number of field isolates $(9,13,14,21,22)$. Interestingly, $\mathrm{mAb}$ 3.1C4 was able to recognize all BVDV isolates tested so far. This suggests that it binds to a highly conserved epitope within E2/ gp53, which is possibly involved in an important biological function and therefore is under strong variability constraint. Furthermore, the epitope recognized by mAb 3.1C4 seems to be required for initiation of infection since viral infectivity was substantially reduced following virus-neutralization assays. To date, only a few broadly reactive $\mathrm{mAbs}$ against E2/gp53 have been described (14). Nevertheless, testing mAb 3.1C4 with a higher number of BVDV isolates will be necessary in order to unequivocally ascertain whether the epitope recognized is indeed thoroughly conserved.

The binding specificity of mAb 6.F11 was directed to the structural protein E1/ gp25, which is an envelope protein covalently attached to the E2/gp53 glycoprotein (3). The role of E1/gp25 remains to be determined. Nonetheless, because mAb 6.F11 was also broadly reactive to BVDV isolates, it is conceivable that this protein contains epitopes that are thoroughly conserved and might be exploited as an important diagnostic tool.

Although mAbs 3.1C4 and 6.F11 recognized all BVDV isolates tested, they failed to react with a few $\mathrm{HCV}$ isolates tested so far. If this property holds true for other HCV isolates, it may be exploited to distinguish pestivirus infection of pigs in areas where $\mathrm{HCV}$ eradication programs are underway and rapid diagnosis is required. In addition, because the epitopes recognized by these $\mathrm{mAbs}$ are located in viral structural proteins, they might be useful to develop immunology-based diagnostic tests such as antigen capture ELISA or IPX with the main objec- 
tive of identifying persistently infected animals in a herd.

\section{Acknowledgments}

We thank Dr. Claudio Canal (UFRGS, Porto Alegre, RS) for determining the immunoglobulin class, Dr. Paulo M. Roehe
(CPVDF, Eldorado do Sul, RS), Dr. Valéria Moojen (Faculdade de Veterinária, UFRGS, Porto Alegre, RS), Dr. Maristela Pituco (Instituto Biológico de São Paulo), Dr. Anselmo Odeon (INTA Balcarce, Argentina), and Dr. Elba Laura Weber (INTA Castelar, Argentina) for providing some of the BVDV isolates used in this study.

\section{References}

1. Collett MS, Larson R \& Belzer SK (1988). Proteins encoded by bovine viral diarrhea virus: the genomic organization of a pestivirus. Virology, 165: 200-208.

2. Meyers G \& Thiel HJ (1996). Molecular characterization of pestiviruses. Advances in Virus Research, 47: 53-118.

3. Donis RO (1995). Molecular biology of bovine viral diarrhea virus and its interactions with the host. Veterinary Clinics of North America, 11: 393-424.

4. Donis RO \& Dubovi EJ (1987). Differences in virus-induced polypeptides in cells infected by cytopathic and noncytopathic biotypes of bovine virus diarrhea-mucosal disease virus. Virology, 156: 168-173.

5. Pellerin C, Hurk J VD \& Lecomte J (1994). Identification of a new group of bovine viral diarrhea virus strains associated with severe outbreaks and high mortalities. Virology, 203: 260-268.

6. Ridpath J F, Bolin SR \& Dubovi EJ (1994). Segregation of bovine viral diarrhea virus into genotypes. Virology, 205: 66-74.

7. Wengler G, Bradley DW, Collet MS, Heinz FX, Schlesinger RW \& Strauss J H (1995). Flaviviridae. Virus Taxonomy: Sixth Report of the International Committee on Taxonomy of Viruses. Archives of Virology (Suppl 10): 415-427.

8. Baker JC (1995). The clinical manifestations of bovine viral diarrhea infection. Veterinary Clinics of North America, 11: 425-446.

9. Edwards S \& Paton D (1995). Antigenic differences among pestiviruses. Veterinary Clinics of North America, 11: 563578.

10. Dubovi EJ (1992). Genetic diversity and BVD virus. Comparative Immunology, Microbiology and Infectious Diseases, 15: 155-162.
11. Howard CJ, Brownlie J \& Clarke MC (1987). Comparison by the neutralization assay of pairs of non-cytopathogenic and cytopathogenic strains of bovine virus diarrhoea virus isolated from cases of mucosal disease. Veterinary Microbiology, 13: 361-369.

12. Botton AS, da Silva AM, Brum MCS, Weiblen R \& Flores EF (1998). Antigenic characterization of Brazilian bovine viral diarrhea virus isolates by monoclonal antibodies and cross-neutralization. Brazilian J ournal of Medical and Biological Research, 31: 1429-1438.

13. Paton $D J$, Lowings $J P \&$ Barrett $A D T$ (1992). Epitope mapping of the gp53 envelope protein of bovine viral diarrhea virus. Virology, 190: 763-772.

14. Corapi WV, Donis RO \& Dubovi EJ (1990). Characterization of a panel of monoclonal antibodies and their use in the study of the antigenic diversity of bovine viral diarrhea virus. American J ournal of Veterinary Research, 51: 1388-1394.

15. Odeon AC, Kelling CL, Marshall DJ , Estela ES, Dubovi EJ \& Donis R (1999). Experimental infection of calves with bovine viral diarrhea virus genotype II (NY-93). J ournal of Veterinary Diagnostic Investigation, 11: 221-228.

16. Botton SA, Gil LHVG, Silva AM, Flores EF, Weiblen R, Pituco EM, Roehe PM, Moojen V \& Wendelstein AC (1998). Caracterização preliminar de amostras do vírus da diarréia viral bovina (BVDV) isoladas no Brasil. Brazilian J ournal of Veterinary Research, 18: 84-92.

17. Fuerst TR, Niles EG, Studier FW \& Moss B (1986). Eukaryotic transient-expression system based on recombinant vaccinia virus that synthesizes bacteriophage $\mathrm{T7}$ RNA polymerase. Proceedings of the Na- tional Academy of Sciences, USA, 83: 8122-8126.

18. Vassilev V, Collet MS \& Donis RO (1997) Authentic and chimeric full-length genomic CDNA clones of bovine viral diarrhea virus that yield infectious transcripts. J ournal of Virology, 71: 471-478.

19. Baker J C (1987). Bovine viral diarrhea virus: a review. J ournal of the American Veterinary Medical Association, 190: 1449-1458.

20. Oliveira G, Oliveira EAS, Silva LTH, Vieira LA, Hoffmann VL, Fernandes GV, Silva TC, Caldas APF \& Roehe PM (1996). Presença de pestivirus e anticorpos contra pestivirus em soros e cultivos celulares. Arquivos Brasileiros de Medicina Veterinária e Zootecnia, 48: 513-521.

21. Bolin SR, M oennig V \& Gourley NE (1988). Monoclonal antibodies with neutralizing activity segregate isolates of bovine viral diarrhea virus into groups. Archives of Virology, 99: 117-123.

22. Deregt $\mathrm{D}$, van Rijn PA, Wiens TY \& van den HurkJ (1998). Monoclonal antibodies to the E2 protein of a new genotype (type 2 ) of bovine viral diarrhea virus define three antigenic domains involved in neutralization. Virus Research, 57: 171-181.

23. Wharton SA, Weis W, Skehel JJ \& Wiley DC (1989). Structure, function and antigenicity of the hemagglutinin of influenza virus. In: Krug RM (Editor), The Influenza. Plenum Press, New York, 153-173.

24. McKeating JA, Moore JP, Ferguson $M$, Graham S, Almond J W, Evans DJ \& Weiss RA (1992). Monoclonal antibodies to the c4 region of human immunodeficiency virus type 1 gp120: use of topological analysis of a CD4 binding site. AIDS Research and Human Retroviruses, 8: 451-459. 